\title{
Public-Private Partnerships in Emerging Markets
}

\section{Nathan Hayes, alumni from the department of International Development, looks at arguments for and against public-private partnerships (PPPs) in emerging markets.}

Emerging markets face the challenge of meeting growing demand for new and better infrastructure services. The World Investment Report 2014 from UNCTAD estimates that the infrastructure investment gap faced by developing countries is some US\$1.6 trillion over the period 2015 to 2030. As available funding from traditional sources and capacity in the public sector to implement many projects at one time remains limited, governments have found that partnerships with the private sector are an attractive alternative to increase and improve the supply of infrastructure services.

Public-private partnerships (PPPs) are a mechanism for governments to procure, implement, and manage public infrastructure and services projects utilising the resources and expertise of the private sector. PPPs combine the skills and resources of both the public and private sectors through sharing of risks and responsibilities. This enables governments focus instead on policy, planning and regulation by delegating day-to-day operations.

\section{Need for PPPs in Emerging Markets}

Properly implementing and managing PPPs can create a number of benefits, both directly and indirectly, begetting further economic growth, policy reform, and creating downstream opportunities across a number of different areas of the economy.

PPPs can supplement public sector capacities to meet the demand for infrastructure development. This is particularly true in many developing countries, with relatively limited government capacity, combined with demand for infrastructure from growing populations.

PPPs can provide relief from the burden of the costs of design and construction for governments. Moreover, the involvement of the private sector, which should be profit-maximising, will help ensure greater efficiency throughout such projects.

Similarly, co-operating in PPP projects can aid in the development of local private sector capabilities through joint ventures with large international firms, and can also provide subcontracting opportunities for local firms.

\section{Issues with the Private Sector in Emerging Markets}

The private sector plays an important role as an engine of economic growth and job creation. It provides goods and services, begets innovation and creativity, and generates tax revenues to finance essential social and economic infrastructure. However, the private sector in many developing countries is relatively nascent, and faces a number of structural challenges to its proper and efficient functioning.

One such challenge is corruption, experienced directly by firms themselves or in the perception that the political system as a whole is corrupt. 
Many developing countries still suffer from relatively weak business environments, particularly regarding poor regulatory environments, tax environments, and ease of operating a business or gaining the necessary trade permits.

Another major obstacle to private sector development is political instability. In order to overcome this, governments need to boost transparency, improve governance and enhance competition.

Unreliable supplies of electricity and poor infrastructure more broadly can greatly harm the development of a vibrant domestic private sector, hampering economic growth, and adding significant costs and delays to international trade.

Poor access to finance can undermine private sector growth. Credit environments in many emerging markets remain weak, and it can be difficult even for large companies to raise the necessary funds, particularly for large infrastructure programmes. More broadly, shallow financial markets can hamper growth of the private sector.

\section{Issues with PPPs in Emerging Markets}

There are a number of issues with implementing PPPs in emerging markets. Such challenges arise due to problems with both the public and private sectors in these environments combined with unique and additional challenges to implementing PPP projects.

Although many governments have implemented processes to promote PPPs, a general lack of technical capacity in the public sector remains a major problem. In the absence of established institutional arrangements, public officials face difficulties in project development and implementation. Moreover, many infrastructure projects have a positive social rate of return, but a negative financial one.

\section{SOEs in Emerging Markets}

A State Owned Enterprise (SOE) is a legal entity created by the government to undertake commercial activities on the government's behalf. SOEs can play a vital role in emerging markets; entities operating in the private sector with the support of their government can overcome many barriers to growth ubiquitous in emerging markets.

SOEs are particularly well-suited to take on PPP projects, particularly those undertaken in emerging markets. This is primarily due to reluctance from the private sector to engage with the public sector in many such markets, combined with poor business environments and commercially unattractive projects.

Indeed, the low returns on PPPs make them unattractive for private firms; many infrastructure projects are for the public good, but generate low returns for operators.

Private firms are less resilient than SOEs; the latter can take a financial hit if the project fails, while private companies would likely be ruined. This is particularly salient in environments without legal frameworks to deal with project failure.

Many private firms are weary of abuse and corruption from the government and believe that they are likely to receive limited legal protection in event of a dispute.

Long-term investments should generate low but stable returns with low risk, but this is not the case for PPPs in emerging markets - municipal infrastructure plans can change quickly, $s \circ \wedge$ iv ate 
firms find it difficult to foresee returns on their investments.

From the government's perspective, SOEs are preferred partners. In many countries, there is still a paucity of legislation specifically regulating PPPs. This creates a great deal of uncertainty for all potential partners in such an arrangement. This can create an environment of public-public partnerships, with many of the benefits of private sector participation lost. With no actual private sector involvement, the public sector must finance the whole project. While debt pressure will be relieved for some government departments, it will ultimately end up on the books of another arm of the state. Such measures are likely to crowd-out the private sector, particularly in environments where it must jostle for scarce capital.

Nathan Hayes is currently an Economist at Timetric's Construction Intelligence Centre. He Holds a BSc in Economics and Politics from the University of Southampton and MSc in Political Economy of Late Development from the London School of Economics and Political Science.

The views expressed in this post are those of the author and in no way reflect those of the International Development LSE blog or the London School of Economics and Political Science. 